\title{
Hypopyon as the first sign of relapse in acute lymphoblastic leukaemia
}

\author{
Daniela Barraco • Anna Candoni · Erica Simeone • \\ Angelo Pirracchio $\cdot$ Renato Fanin
}

Received: 17 October 2012/Revised: 19 January 2013/Accepted: 20 January 2013/Published online: 12 February 2013

(C) The Japanese Society of Hematology 2013

Ocular localizations ranging from leukemic retinopathy to involvement of the iris and anterior chamber may be observed as clinical manifestations of acute lymphoblastic leukaemia (ALL). Involvement of the anterior ocular segment is very rare in adult ALL, and is found in less than $1 \%$ of leukaemic relapses [1,2]. We report a case of leukemic hypopyon, secondary to sedimentation of leukemic blast cells in the ocular anterior chamber, occurring in a 62-year-old woman with T-ALL who was treated with the induction chemotherapy including methotrexate, cytarabine, cyclophosphamide, doxorubicin, vincristine, and dexamethasone, also with a central nervous system (CNS) prophylaxis, and achieved a complete remission. Fourteen months after the first complete remission, while receiving maintenance therapy (mercaptopurine and methotrexate), the patient complained of an ipsilateral reduction of visual acuity on the left associated with changes in head position. Ophthalmic evaluation was performed, showing a leukemic hypopyon with a horizontal fluid level (measuring $3 \mathrm{~mm}$ ) in the left eye. The patient refused anterior chamber paracentesis. A lumbar puncture revealed CNS relapse with 50 blast cells/ $\mu \mathrm{L}$ of cerebrospinal fluid (CSF). The lymphoid blasts were positive for CD7, CD5, CD2, and CD13. Although the patient was treated with intrathecal chemotherapy with methotrexate and cytarabine, and later with liposomal cytarabine, with a clearing of malignant cells

D. Barraco · A. Candoni $(\bowtie) \cdot$ E. Simeone $\cdot$ R. Fanin Division of Hematology, University of Udine, Udine, Italy e-mail: candoni.anna@aoud.sanita.fvg.it

\footnotetext{
A. Pirracchio

Division of Opthalmology, University of Udine, Udine, Italy
}

from the CSF, a worsening of the anterior chamber hypopyon was noted and the patient required ocular radiotherapy with a transient and partial response. The patient died (7 months after the diagnosis of hypopyon) with ocular, cutaneous, and bone marrow leukemic involvement.

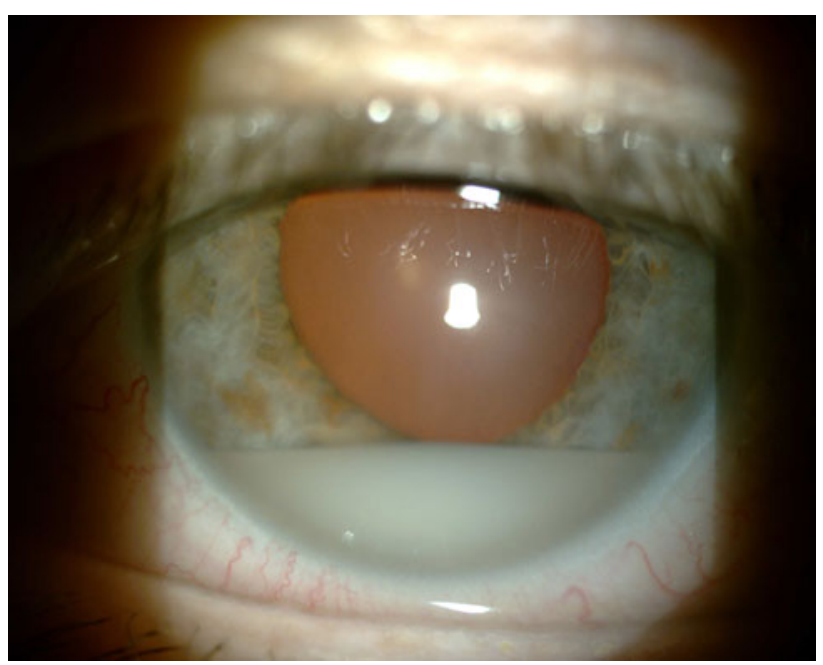

\section{References}

1. Yi DH, Rashid S, Cibas ES, Arrigg PG, Dana MR. Acute unilateral leukemic hypopyon in an adult with relapsing acute lymphoblastic leukemia. Am J Ophthalmol. 2005;139:719-21.

2. Wetzler M. Unusual manifestations of acute leukemia. Case 3. Unilateral leukemic hypopyon. J Clin Oncol. 2000;18(19): $3439-40$. 